Article

\title{
Antioxidant Activity and Molecular Docking Study of Volatile Constituents from Different Aromatic Lamiaceous Plants Cultivated in Madinah Monawara, Saudi Arabia
}

\author{
Amr Farouk $^{1, *}$, Mohamed Mohsen ${ }^{2}$, Hatem Ali ${ }^{3,4}$, Hamdy Shaaban ${ }^{1}$ and Najla Albaridi ${ }^{5}$ (D) \\ 1 Flavour and Aroma Chemistry Department, National Research Center, Cairo 12622, Egypt; \\ hamdy_asn@yahoo.com \\ 2 Madinah Region Municipality-Quality Agency-Food and Environment Laboratory, P.O. Box 4952, \\ Al-Madina Al-Munawara 41412, Saudi Arabia; mohmedmohsen28@gmail.com \\ 3 Food Technology Department, National Research Center, Cairo 12622, Egypt; haali@ksu.edu.sa \\ 4 Food Science and Nutrition Department, College of Food Science and Agriculture, King Saud University, \\ Riyadh 12372, Saudi Arabia \\ 5 Department of Physical Sport Science, Nutrition and Food Science, Princess Nourah Bint Abdulrahman \\ University, P.O. Box 84428, Riyadh 11671, Saudi Arabia; naalbaridi@pnu.edu.sa \\ * Correspondence: amrfarouk01@gmail.com; Tel.: +20-1092327777
}

check for updates

Citation: Farouk, A.; Mohsen, M.; Ali, H.; Shaaban, H.; Albaridi, N. Antioxidant Activity and Molecular Docking Study of Volatile

Constituents from Different Aromatic Lamiaceous Plants Cultivated in Madinah Monawara, Saudi Arabia. Molecules 2021, 26, 4145. https://doi.org/10.3390/ molecules26144145

Academic Editors:

Agnieszka Szewczyk, Inga Kwiecien and Ladislav Kokoška

Received: 1 June 2021

Accepted: 26 June 2021

Published: 7 July 2021

Publisher's Note: MDPI stays neutral with regard to jurisdictional claims in published maps and institutional affiliations.

Copyright: (c) 2021 by the authors. Licensee MDPI, Basel, Switzerland. This article is an open access article distributed under the terms and conditions of the Creative Commons Attribution (CC BY) license (https:/ / creativecommons.org/licenses/by/ $4.0 /)$.

\begin{abstract}
A comparative study of volatile constituents, antioxidant activity, and molecular docking was conducted between essential oils from Mentha longifolia L., Mentha spicata L., and Origanum majorana L., widely cultivated in Madinah. The investigation of volatile oils extracted by hydrodistillation was performed using Gas Chromatography-Mass Spectrometry (GC-MS). A total number of 29, 42, and 29 components were identified in M. longifolia, M. spicata, and O. majorana representing, respectively, 95.91, 94.62, and 98.42, of the total oils. Pulegone (38.42\%), 1,8-cineole (15.60\%), menthone $(13.20 \%)$, and isopulegone $(9.81 \%)$ were the dominant compounds in M. longifolia oil; carvone (35.14\%), limonene $(27.11 \%)$, germacrene D (4.73\%), and $\beta$-caryophyllene $(3.02 \%)$ were dominant in M. spicata oil; terpin-4-ol (42.47\%), trans-sabinene hydrate $(8.52 \%), \gamma$-terpinene $(7.90 \%)$, $\alpha$-terpineol $(7.38 \%)$, linalool $(6.35 \%), \alpha$-terpinene $(5.42 \%)$, and cis-sabinene hydrate $(3.14 \%)$ were dominant in O. majorana oil. The antioxidant activity, assessed using DPPH free radical-scavenging and ABTS assays, was found to be the highest in O. majorana volatile oil, followed by M. spicata and M. longifolia, which is consistent with the differences in total phenolic content and volatile constituents identified in investigated oils. In the same context, molecular docking of the main identified volatiles on NADPH oxidase showed a higher binding affinity for cis-verbenyl acetate, followed by $\beta$-elemene and linalool, compared to the control (dextromethorphan). These results prove significant antioxidant abilities of the investigated oils, which may be considered for further analyses concerning the control of oxidative stress, as well as for their use as possible antioxidant agents in the pharmaceutical industry.
\end{abstract}

Keywords: essential oil; GC-MS; Mentha longifolia L.; Mentha spicata L.; Origanum majorana L.; antioxidant potential; oxidative stress; in silico studies

\section{Introduction}

Madinah Munawara is an important city in the Middle East with a relevant historical heritage and millions of visitors annually, located at the northwest of the Arab peninsula. Agriculture is one of the main activities in Madinah, with many crops, including medicinal plants [1]. Medicinal plants represent about $12 \%$ of the total floral species in the Arab peninsula and include 300 species belonging to 72 families. The Lamiaceae, also known as Labiatae or the mint family, is widely grown in the Arab peninsula, especially in Madinah. Mentha longifolia L. (Madany or Habak), Mentha spicata L. (Balady), and Origanum majorana L. (Doosh) are traditionally used alone or mixed with tea and other herbs as refreshment drinks and in cuisine dishes for their aroma and flavor. Moreover, such mints are used 
in folk medicine to treat nausea, bronchitis, anorexia, ulcerative colitis, liver diseases, and other symptoms [2]. The Lamiaceae family contains 236 genera, with M. longifolia and M. spicata belonging to the genus Mentha L. and O. majorana belonging to the genus Origanum L.

The biological activity of the essential oils of M. longifolia cultivated in Madinah has been studied by many authors and associated with antimicrobial, antimalarial, antileishmanial, antioxidant, antimutagenic, and other activities [3-5]. M. longifolia displayed a lower antimicrobial activity against Leishmania donovani promastigotes compared to other lamiaceous plants, like Mentha australis or Teucrium polium L., and also lower antifungal properties toward Candida krusei and C. glabrata [4]. In contrast, M. longifolia oil possesses stronger antioxidant and antibacterial activity compared to $M$. polegium, due to its higher flavonoid content, which makes it a good protector for cardiovascular and throat health [3,5]. The chemical composition of M. longifolia cultivated in Madinah is a debated issue because of remarkable discrepancies, raising the need for more investigation of the oil $[4,6,7]$. To the best of our knowledge, no reports have analyzed the biological activity of M. spicata or O. majorana cultivated in Madinah. However, the essential oil of M. spicata cultivated in Pakistan and Tunisia displayed effectively scavenged DPPH free radicals, inhibition of linoleic acid peroxidation, and high activity against $S$. epidermidis and $S$. aureus, as well as Gram-negative cells of Salmonella spp. and E. coli [5]. Similarly, O. majorana oil showed antioxidant, antimicrobial, cytotoxic, and acetylcholinesterase properties based on plants cultivated in Tunisia [8].

The antioxidant activity plays an important role in the regulation of redox homeostasis and oxidative stress reduction. Reactive oxygen species (ROS) generated during oxidation and rancidity of fats and oils are the main reason for oxidative damage, which causes cell or oxidative stress associated with many chronic diseases, like diabetes, cancer, and cardiovascular disorders. Therefore, antioxidants are used extensively to maintain the balance of redox homeostasis and reduced levels of oxidative stress [9]. Nowadays, molecular docking has been applied as a mechanistic tool to study the inhibition of enzymes that negatively affect antioxidant activity, like NADPH oxidase (NO), which is responsible for ROS generation [10].

The present study aimed to investigate chemical constituents of M. longifolia essential oil cultivated in Madinah to clarify the contradiction found in the literature, and also to unveil the volatile constituents of $M$. spicata and O. majorana. The antioxidant activity of the investigated oils was evaluated based on DPPH radical scavenging and $\beta$-carotene bleaching assays with the determination of the total phenolic content. The antioxidant potential of the main volatiles was evaluated in silico through molecular docking with NO enzyme, using dextromethorphan (DEX) as a positive control. The investigation of such Lamiaceae species opens the perspective towards a better understanding of their biological efficiency and its interpretation based on the chemical composition of the studied oils.

\section{Results and Discussion}

\subsection{Chemical Composition of Volatile Oils}

Hydrodistillation of the plant samples under investigation produced colorless to pale yellow oil, with $0.32 \pm 0.05,0.29 \pm 0.04$, and $0.26 \pm 0.06 \%$ in Madinah essential oil and $0.42 \pm 0.08 \%$ for M. longifolia, M. spicata, and O. majorana, respectively. The percentage yield was calculated on a dry weight basis. The chemical composition of volatile oils from aerial parts of M. longifolia, M. spicata, and O. majorana was characterized by GC-MS (Table 1, Figure 1A-C). A total number of 29, 42, and 29 components were identified, representing respectively $95.91,94.62$, and $98.42 \%$ of the total oils. Pulegone $(38.42 \%), 1,8$-cineole $(15.60 \%)$, menthone $(13.20 \%)$, and isopulegone $(9.81 \%)$ were the dominant compounds in the M. longifolia oil, which is consistent with Ibrahim et al. [4], who studied the same species in Abyar Al-Mashy, Madinah, despite remarkable quantitative differences due to geographical variation (Table 1, Figure 1A). In contrast, entirely different profiles were revealed by Salman et al. [7] and Anwar et al. [6], the first study reporting menthone, 
eucalyptol, and isomenthone, while the second one reporting carvone, limonene, and dihydrocarveol as the major components. Our above findings are in line with previous reports on volatiles of the same species cultivated in Egypt [11], with quantitative differences, while the essential oils of M. longifolia cultivated in Tunisia and Tajikistan have an entirely different profile $[12,13]$. This is likely due to differences in environmental and geographic conditions.

Table 1. Identification of the volatile constituents of M. longifolia, M. spicata, and O. majorana oils using GC-MS.

\begin{tabular}{|c|c|c|c|c|c|c|c|}
\hline \multirow{2}{*}{ S/N } & \multirow{2}{*}{ Compound } & \multirow{2}{*}{$\mathbf{R I}^{\mathbf{a}}$} & \multirow{2}{*}{ LRI $^{b}$} & \multicolumn{3}{|c|}{ Area \% } & \multirow{2}{*}{$\begin{array}{l}\text { Identification } \\
\text { Method }^{\mathrm{c}}\end{array}$} \\
\hline & & & & M. longfolia & M. spicata & O. majorana & \\
\hline 1 & Methyl cyclohexane & 726 & 716 & $0.90 \pm 0.05$ & n.d. & n.d. & RI, MS \\
\hline 2 & 3-Hexen-1-ol & 855 & 851 & n.d. & $1.33 \pm 0.6$ & $0.46 \pm 0.06$ & RI, MS \\
\hline 3 & $\alpha$-Thujene & 932 & 931 & n.d. & $0.51 \pm 0.14$ & $0.12 \pm 0.04$ & RI, MS \\
\hline 4 & $\alpha$-Pinene & 937 & 939 & 0.74 & $0.65 \pm 0.11$ & $0.18 \pm 0.07$ & RI, MS \\
\hline 5 & 3-Methyl cyclohexanone & 955 & 952 & $0.31 \pm 0.06$ & n.d. & n.d. & RI, MS \\
\hline 6 & Sabinene & 978 & 976 & $3.09 \pm 0.92$ & $0.50 \pm 0.04$ & $2.50 \pm 1.05$ & RI, MS, STD \\
\hline 7 & $\beta$-Pinene & 982 & 980 & $2.25 \pm 0.61$ & n.d. & n.d. & RI, MS, STD \\
\hline 8 & $\alpha$-Myrcene & 986 & 991 & n.d. & $0.66 \pm 0.07$ & $1.19 \pm 0.73$ & RI, MS, STD \\
\hline 9 & 3-Octanol & 992 & 993 & n.d. & $1.04 \pm 0.08$ & n.d. & RI, MS \\
\hline 10 & $\alpha$-Phellandrene & 1003 & 1005 & n.d. & n.d. & $0.34 \pm 0.09$ & RI, MS \\
\hline 11 & $\alpha$-Terpinene & 1017 & 1018 & n.d. & $0.07 \pm 0.01$ & $5.42 \pm 1.42$ & RI, MS, STD \\
\hline 12 & $p$-Cymene & 1025 & 1026 & $0.20 \pm 0.03$ & $0.11 \pm 0.02$ & $0.57 \pm 0.1$ & RI, MS \\
\hline 13 & Limonene & 1034 & 1031 & $0.49 \pm 0.06$ & $27.11 \pm 2.6$ & $2.57 \pm 0.94$ & RI, MS, STD \\
\hline 14 & 1,8-Cineole & 1039 & 1033 & $15.60 \pm 1.21$ & $0.61 \pm 0.08$ & $0.33 \pm 0.05$ & RI, MS, STD \\
\hline 15 & $\beta$-Ocimene (Z-) & 1042 & 1040 & n.d. & $0.08 \pm 0.02$ & n.d. & RI, MS \\
\hline 16 & $\beta$-Ocimene $(E-)$ & 1052 & 1050 & n.d. & $0.14 \pm 0.03$ & n.d. & RI, MS \\
\hline 17 & $\gamma$-Terpinene & 1063 & 1062 & n.d. & $0.33 \pm 0.08$ & $7.90 \pm 1.45$ & RI, MS, STD \\
\hline 18 & cis-Sabinene hydrate & 1070 & 1068 & n.d. & $0.18 \pm 0.04$ & $3.14 \pm 0.76$ & RI, MS \\
\hline 19 & Terpinolene & 1090 & 1088 & n.d. & $0.18 \pm 0.03$ & n.d. & RI, MS \\
\hline 20 & trans-Sabinene hydrate & 1098 & 1097 & $0.36 \pm 0.09$ & n.d. & $8.52 \pm 1.14$ & RI, MS \\
\hline 21 & Linalool & 1101 & 1098 & $0.10 \pm 0.02$ & $0.10 \pm 0.01$ & $6.35 \pm 1.09$ & RI, MS, STD \\
\hline 22 & $p$-Menth-8-en-1-ol & 1142 & 1140 & n.d. & n.d. & $1.24 \pm 0.47$ & RI, MS \\
\hline 23 & Verbenol & 1144 & 1140 & $0.28 \pm 0.08$ & n.d. & n.d. & RI, MS \\
\hline 24 & cis- $\beta$-Terpineol & 1146 & 1144 & n.d. & $0.59 \pm 0.06$ & n.d. & RI, MS \\
\hline 25 & Isothujanol & 1149 & 1146 & $0.18 \pm 0.04$ & n.d. & n.d. & RI, MS \\
\hline 26 & Menthone & 1155 & 1154 & $13.20 \pm 2.4$ & $0.83 \pm 0.53$ & n.d. & RI, MS, STD \\
\hline 27 & Isopulegone & 1177 & 1174 & $9.81 \pm 1.1$ & n.d. & n.d. & RI, MS \\
\hline 28 & Terpin-4-ol & 1180 & 1177 & n.d. & $\mathbf{1 . 7 6} \pm 0.89$ & $42.47 \pm 3.12$ & RI, MS, STD \\
\hline 29 & Isomenthol & 1183 & 1182 & $1.58 \pm 0.8$ & n.d. & n.d. & RI, MS \\
\hline 30 & $\alpha$-Terpineol & 1191 & 1189 & $1.57 \pm 0.9$ & n.d. & $7.38 \pm 1.03$ & RI, MS, STD \\
\hline 31 & Dihydrocarveol & 1192 & 1192 & n.d. & $1.33 \pm 0.93$ & $1.89 \pm 0.73$ & RI, MS \\
\hline 32 & cis-Dihydrocarvone & 1195 & 1193 & n.d. & 0.6 & n.d. & RI, MS \\
\hline 33 & Verbenone & 1207 & 1204 & $0.66 \pm 0.1$ & n.d. & n.d. & RI, MS \\
\hline 34 & Pulegone & 1240 & 1237 & $38.42 \pm 3.9$ & n.d. & n.d. & RI, MS, STD \\
\hline 35 & Carvone & 1244 & 1242 & $0.80 \pm 0.12$ & $35.14 \pm 3.72$ & n.d. & RI, MS, STD \\
\hline 36 & Piperitone & 1251 & 1252 & 0.2 & $0.27 \pm 0.05$ & n.d. & RI, MS \\
\hline 37 & Linalyl acetate & 1261 & 1257 & n.d. & n.d. & $0.27 \pm 0.08$ & RI, MS \\
\hline 38 & cis-Verbenyl acetate & 1283 & 1282 & $1.75 \pm 0.83$ & n.d. & n.d. & RI, MS \\
\hline 39 & Bornyl acetate & 1287 & 1285 & n.d. & $0.50 \pm 0.18$ & n.d. & RI, MS \\
\hline 40 & Menthyl acetate & 1291 & 1294 & n.d. & $0.29 \pm 0.02$ & n.d. & RI, MS \\
\hline 41 & $\delta$-Terpinyl acetate & 1307 & 1313 & n.d. & n.d. & $0.16 \pm 0.02$ & RI, MS \\
\hline 42 & Dihydrocavyl acetate (iso-) & 1338 & 1325 & n.d. & $0.12 \pm 0.07$ & n.d. & RI, MS \\
\hline
\end{tabular}


Table 1. Cont.

\begin{tabular}{|c|c|c|c|c|c|c|c|}
\hline \multirow{2}{*}{ S/N } & \multirow{2}{*}{ Compound } & \multirow{2}{*}{$\mathrm{RI}^{\mathrm{a}}$} & \multirow{2}{*}{ LRI $^{b}$} & \multicolumn{3}{|c|}{ Area $\%$} & \multirow{2}{*}{$\begin{array}{l}\text { Identification } \\
\text { Method }^{\mathrm{c}}\end{array}$} \\
\hline & & & & M. longfolia & M. spicata & O. majorana & \\
\hline 43 & trans-Carvyl acetate & 1347 & 1337 & n.d. & $0.12 \pm 0.08$ & n.d. & RI, MS \\
\hline 44 & $\delta$-Elemene & 1350 & 1339 & n.d. & n.d. & $0.12 \pm 0.01$ & RI, MS \\
\hline 45 & cis-Carvyl acetate & 1363 & 1362 & n.d. & $0.40 \pm 0.06$ & n.d. & RI, MS \\
\hline 46 & Neryl acetate & 1369 & 1365 & n.d. & n.d. & $0.86 \pm 0.16$ & RI, MS \\
\hline 47 & $\alpha$-Copaene & 1367 & 1376 & n.d. & $0.18 \pm 0.06$ & $0.22 \pm 0.04$ & RI, MS \\
\hline 48 & $\beta$-Bourbonene & 1376 & 1384 & n.d. & $2.27 \pm 0.79$ & n.d. & RI, MS \\
\hline 49 & Geranyl acetate & 1381 & 1383 & n.d. & n.d. & $0.27 \pm 0.06$ & RI, MS \\
\hline 50 & $\beta$-Elemene & 1392 & 1391 & n.d. & $1.75 \pm 0.45$ & n.d. & RI, MS \\
\hline 51 & cis-Jasmone & 1400 & 1394 & n.d. & $0.49 \pm 0.17$ & n.d. & RI, MS \\
\hline 52 & $\beta$-Caryophyellene & 1428 & 1418 & $0.97 \pm 0.21$ & $3.02 \pm 1.05$ & $1.77 \pm 0.54$ & RI, MS, STD \\
\hline 53 & $\gamma$-Elemene & 1430 & 1433 & n.d. & n.d. & $1.67 \pm 0.66$ & RI, MS \\
\hline 54 & $\alpha$-Humulene & 1450 & 1454 & $0.13 \pm 0.06$ & $0.38 \pm 0.02$ & n.d. & RI, MS \\
\hline 55 & Muurola-4(14),5-diene (cis-) & 1464 & 1460 & $0.13 \pm 0.08$ & n.d. & n.d. & RI, MS \\
\hline 56 & $\gamma$-Muurolene & 1478 & 1477 & n.d. & $2.75 \pm 0.99$ & n.d. & RI, MS \\
\hline 57 & Germacrene D & 1482 & 1480 & $0.42 \pm 0.06$ & $4.73 \pm 1.43$ & n.d. & RI, MS \\
\hline 58 & Bicyclogermacrene & 1496 & 1494 & n.d. & $0.54 \pm 0.34$ & $0.09 \pm 0.02$ & RI, MS \\
\hline 59 & $\alpha$-Muurolene & 1502 & 1499 & $0.16 \pm 0.05$ & $0.84 \pm 0.26$ & n.d. & RI, MS \\
\hline 60 & $\delta$-Cadinene & 1515 & 1524 & $0.22 \pm 0.11$ & $0.36 \pm 0.06$ & n.d. & RI, MS \\
\hline 61 & Spathulenol & 1577 & 1576 & n.d. & $0.33 \pm 0.03$ & $0.26 \pm 0.03$ & RI, MS \\
\hline 62 & Caryophellene oxide & 1582 & 1581 & n.d. & $0.47 \pm 0.08$ & $0.16 \pm 0.01$ & RI, MS \\
\hline 63 & Cubenol & 1641 & 1642 & n.d. & $0.96 \pm 0.21$ & n.d. & RI, MS \\
\hline 64 & $\alpha$-Cadinol & 1655 & 1553 & $0.73 \pm 0.08$ & n.d. & n.d. & RI, MS \\
\hline 65 & Phytol & 1955 & 1949 & $0.66 \pm 0.12$ & n.d. & n.d. & RI, MS \\
\hline- & Total & - & - & 95.91 & 94.62 & 98.42 & \\
\hline
\end{tabular}

${ }^{a}$ RI: retention indices calculated on DB- 5 column using alkanes standards; ${ }^{b}$ LRI: retention indices according to literature; ${ }^{\mathrm{c}}$ Confirmed by comparison with the retention indices, the mass spectrum of the authentic compounds, and the NIST mass spectra library data; n.d: not detected.

The volatile oil extracted from M. spicata showed that carvone (35.14\%), limonene (27.11\%), germacrene D (4.73\%), $\beta$-caryophyllene (3.02\%), $\gamma$-muurolene $(2.75 \%)$, and $\alpha$ bourbonene $(2.27 \%)$ were the predominating compounds (Table 1, Figure 1B). Among the identified components, oxygenated monoterpenes $(42.66 \%)$ are the most abundant, followed by monoterpene hydrocarbons (30.52\%), and finally sesquiterpene hydrocarbons $(16.82 \%)$. The chemical composition of M. spicata volatile oil has been well-documented in many regions, but not in Madinah. In agreement with our findings, previous studies have shown that carvone, limonene, 1,8-cineole, $\beta$-caryophyllene, and germacrene $\mathrm{D}$ are the main components of the M. spicata volatile oil [11,14-16]. Due to differences in ecological parameters, growing location, agronomical practices, as well as environmental conditions, significant variations are expected between M. spicata oil from Madinah and those from other regions, studied by the above researchers. Interestingly, the volatile oil from Madinah appears similar to the Egyptian one. However, they are richer in limonene and oxygenated sesquiterpenes and poor in 1,8-cineol [11].

The oil composition of O. majorana included terpin-4-ol (42.47\%), trans-sabinene hydrate $(8.52 \%), \gamma$-terpinene $(7.90 \%), \alpha$-terpineol $(7.38 \%)$, linalool $(6.35 \%), \alpha$-terpinene $(5.42 \%)$, and cis-sabinene hydrate $(3.14 \%)$ as the main constituents (Table 1, Figure 1C). cisSabinene hydrate may be responsible for the aroma properties of the O. majorana plant since it is characterized by intense, spicy, and marjoram aroma [17]. The detected concentration of terpin-4-ol was higher than the one found in the literature [18-20] possibly due to rearrangements occurring during the distillation process [21]. The volatile oil of Madinah O. majorana displayed a chemotype similar to Central and Eastern Europe, with a relatively 
high concentration of linalool and the absence of sabinene, which may positively affect the biological activity of the oil [18]. In addition to a remarkable quantitative variation, p-cymene and sabinene were found in a higher concentration in China, India, Brazil, Egypt, and Iran $[17,19,20,22,23]$. Again, geographic, climatic, and agronomical aspects are responsible for such variations in oil composition among different cultivation regions [1].

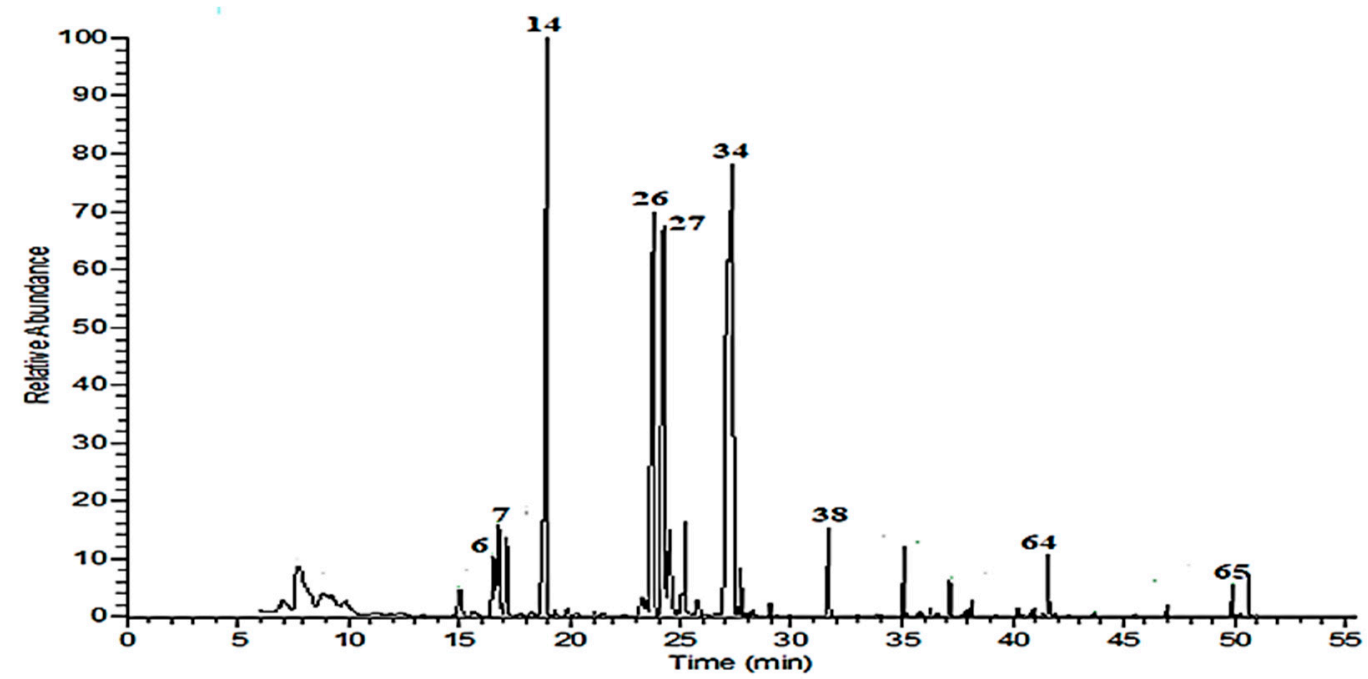

(A)

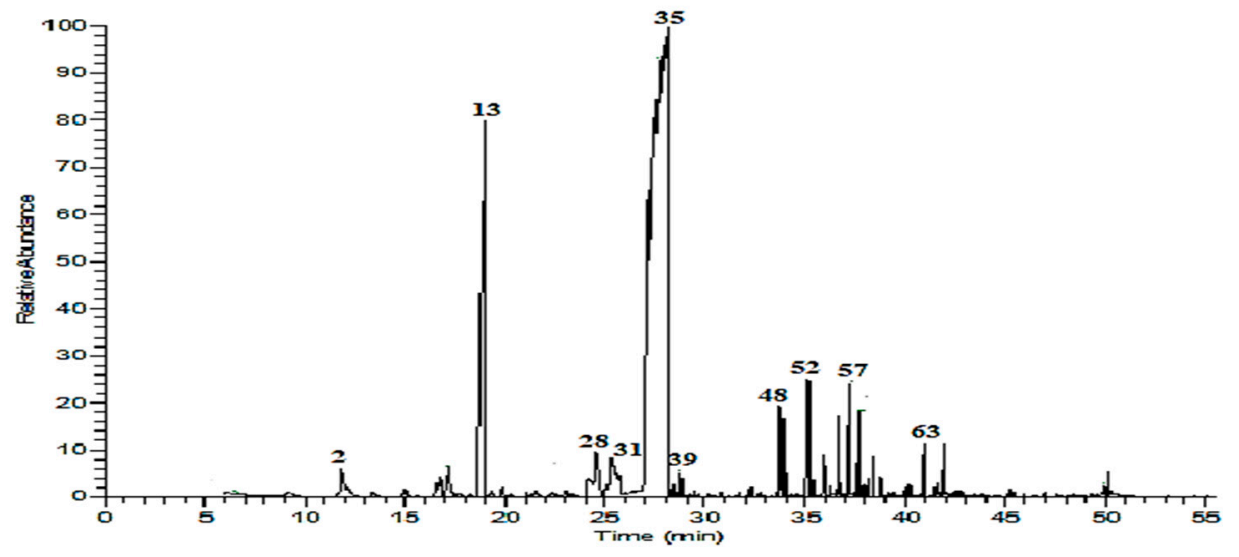

(B)

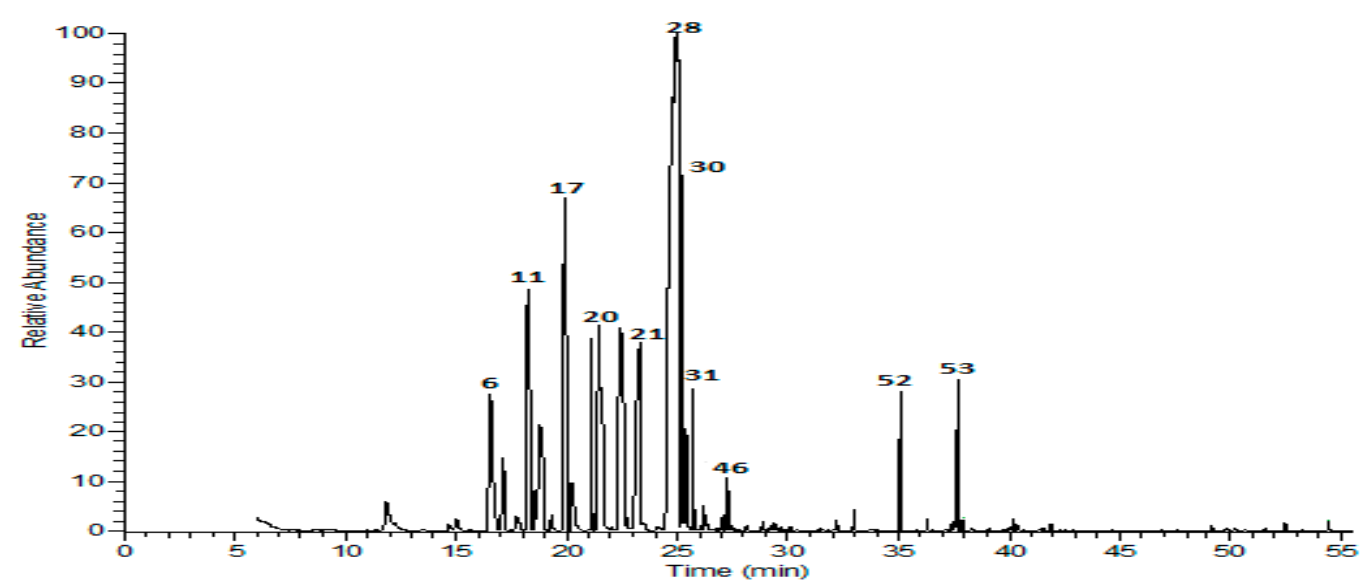

(C)

Figure 1. Volatile chromatograms for Madinah, Saudi Arabia (A) M. longifolia, (B) M. spicata, and (C) O. majorana. 


\subsection{Antioxidant Activity of Volatile Oils}

Oxidative damage is the main cause of many diseases, such as cancer, thus, the application of antioxidant activity tests has become one of the most commonly studied topics [1]. The antioxidant capacity of oils from M. longifolia, M. spicata, and O. majorana cultivated in Madinah was evaluated through DPPH radical scavenging activity, ABTS, radical cation decolorization, and $\beta$-carotene-linoleate bleaching assays, using TBHQ as a positive control (Table 2). The volatile oils displayed an apparent antioxidant capacity [11,12,24], with lower half-maximal inhibitory activity $\left(\mathrm{IC}_{50}\right)$ values indicating higher activity. $\mathrm{O}$. majorana oil exhibited the highest scavenging ability for DPPH $\left(\mathrm{IC}_{50} 1.48 \mathrm{mg} / \mathrm{mL}\right)$, followed by M. spicata $\left(\mathrm{IC}_{50} 3.80 \mathrm{mg} / \mathrm{mL}\right.$ ) and M. longifolia $\left(\mathrm{IC}_{50} 6.68 \mathrm{mg} / \mathrm{mL}\right)$. All the tested samples showed lower DPPH radical scavenging activity when compared with the standard (TBHQ). The $\mathrm{IC}_{50}$ values of oils under investigation are high compared with the previous reports of Hajlaoui et al. [8], Meloni et al. [24], and Tafrihi et al. [4], which indicate lower activity. In other studies, the antioxidant activity of the oils extracted from M. spicata and M. longifolia cultivated in Algeria and Turkey was relatively low, compared with our results $[15,25]$. The different antioxidant activities observed, may be ascribed to different chemical constituents and localities geographic [1]. Table 2 shows a similar trend for radical cation $\left(\mathrm{ABTS}^{\bullet+}\right.$ ) decolorization, with $\mathrm{IC}_{50} 21.32,66.80$, and $87.30 \mu \mathrm{g} / \mathrm{mL}$ for O. majorana, M. spicata, and M. longifolia oils, respectively. In addition, O. majorana oil had a higher inhibitory effect against the oxidation of linoleic acid and the subsequent bleaching of $\beta$-carotene ( $\mathrm{IC}_{50} 10.32 \mathrm{mg} / \mathrm{mL}$ ), in comparison to the oils of $\mathrm{M}$. spicata ( $\mathrm{IC}_{50} 31.18 \mathrm{mg} / \mathrm{mL}$ ) and M. longifolia ( $\mathrm{IC}_{50} 54.30 \mathrm{mg} / \mathrm{mL}$ ).

Table 2. Antioxidant activity of essential oils for M. longifolia, M. spicata, and O. majorana cultivated in Madinah in comparison to the synthetic antioxidant TBHQ.

\begin{tabular}{|c|c|c|c|c|}
\hline Volatile Oil & $\begin{array}{l}\mathrm{IC}_{50}(\mathrm{mg} / \mathrm{mL}) \\
\text { (DPPH) }^{\mathrm{a}}\end{array}$ & $\begin{array}{l}\mathrm{IC}_{50}(\mu \mathrm{g} / \mathrm{mL}) \\
\text { ABTS Assay }\end{array}$ & $\begin{array}{c}\mathrm{IC}_{50}(\mathrm{mg} / \mathrm{mL}) \\
\beta \text {-Carotene Bleaching Assay }\end{array}$ & $\begin{array}{l}\text { Total Phenolic Content }^{\mathrm{a}} \\
\text { mg GA/g (for } 1 \mathrm{mg} / \mathrm{mL} \text { ) }\end{array}$ \\
\hline M. longifolia & $6.68 \pm 0.12$ & $87.30 \pm 1.32$ & $54.30 \pm 0.23$ & $24.10 \pm 0.52$ \\
\hline M. spicata & $3.80 \pm 0.31$ & $66.80 \pm 1.16$ & $31.18 \pm 0.51$ & $42.30 \pm 0.43$ \\
\hline O. majorana & $1.48 \pm 0.08$ & $21.32 \pm 0.72$ & $10.32 \pm 0.41$ & $79.10 \pm 1.01$ \\
\hline (TBHQ) & $1.01 \pm 0.05$ & $12.33 \pm 0.32$ & $4.12 \pm 0.11$ & - \\
\hline
\end{tabular}

${ }^{\mathrm{a}}$ Values represent averages \pm standard deviations for triplicate experiments.

In line with the above findings, Elansary and Ashmawy [11] compared the activity and composition of four mint types and found that the total antioxidant activity of $\mathrm{M}$. spicata, M. piperita, M. longifolia, and M. suaveolens was respectively 79, 31, 21, 6\%, while the results of $\beta$-carotene assay for the same species were $85,55,45,20 \%$. A quite lower level of linoleic acid inhibition of M. longifolia oil (36\%) has been reported by Gulluce et al. [25], compared to the positive control BHT (96\%), in contrast to M. spicata oil (71.2\%) [26]. Carvone has been found to be responsible for antioxidant activity in M. spicata oil, with $\mathrm{IC}_{50} 16.7 \mu \mathrm{g} / \mathrm{mL}$ for the pure terpenoid compound [26]. Further, the presence of limonene as a major component in M. spicata $(27.11 \%$, Table 1$)$ and its combination with caryophyllene (3.02\%, Table 1) may enhance the antioxidant activity of this oil. Limonene exhibited a higher antioxidant activity $(98.74 \%)$ compared to thymol $(98.57 \%)$, linalool (75.88\%), and ascorbic acid (62.43\%) [27]. The volatile oil of M. longifolia showed a low free radical scavenging activity due to the high content of pulegone (38.42\%, Table 1$)$, which has been associated with low reactivity, as reported by Torres-Martíne et al. [27]. In agreement with the present work, pulegone-rich essential oils, such as M. pulegium and M. suaveolens displayed a low free radical scavenging activity [28].

In agreement with the higher total phenolic content and with the presence of active compoundslike linalool (6.35\%, Table 1), O. majorana oil showed the highest antioxidant activity (Table 2). Linalool is a well-known phenolic compound with antioxidant activity $\left(\mathrm{IC}_{50} 0.61 \mu \mathrm{g} / \mathrm{mL}\right.$ ) significantly higher than that of synthetic antioxidants and many essential oils or extracts [29]. In addition, the major component in O. majorana oil is terpin-4-ol (42.47\%, Table 1$)$ that exhibits antioxidant activity as reported in tea tree oil by 
Souza et al. [30]. Mentha species are rich in polyphenols, such as rosmarinic acid, salvianolic acids, hydroxybenzoic acids, caffeoylquinic acids, hydroxycinnamic acids, flavanones, and flavones in M. spicata; rosmarinic acid, salvianolic acid L, dedihydro-salvianolic acid, luteolin-glucuronide, luteolin-diglucuronide, luteolin-glucopyranosyl-rhamnopyranoside, and eriodictyol-glucopyranosyl-rhamnopyranoside in M. longifolia [5]. Similarly, Hossain et al. [31] separated and identified many polyphenols in O. majorana extracts, especially rosmarinic acid by LC-ESI-MS/MS. According to many studies, in addition to the active volatile constituents, antioxidant activity has been correlated to the presence of polyphenols [5].

\subsection{Evaluation of Molecular Docking}

A docking study of the major identified volatiles was conducted on NO to identify the best activity through interaction with the enzyme active sites. The co-crystallized ligands were flexibly re-docked to verify the docking protocol using the MMFF94 force field. The intermolecular interactions between the ligand and the target receptor were evaluated. Validation for the ideal pose was performed by alignment of the X-ray bioactive conformer, with the best-fitted pose of the same compound for the NO. The ideal pose of each molecule was selected according to the energy score and the best fitting to the active site with the least RMSD score.

The binding free energies $(\Delta \mathrm{G})$ for the volatiles docked at NO are shown in Figure 2, revealing the best poses obtained in the molecular docking analyses. The larger the peaks, the lower the $\Delta \mathrm{G}$ and consequently the more significant the interaction between the receptor and the ligands with antioxidant ability. cis-verbenyl acetate identified in M. longifolia displayed the best binding affinity compared to other ligands or the control (DEX), with high docking scores $(-7.4 \mathrm{kcal} / \mathrm{mol})$, followed by $\beta$-elemene $(-6.9 \mathrm{kcal} / \mathrm{mol})$ and linalool $(-6.8 \mathrm{kcal} / \mathrm{mol})$ detected in M. spicata, and O. majorana, respectively.

Figure $3 \mathrm{a}-\mathrm{d}$ show the interaction of cis-verbenyl acetate, $\beta$-elemene, linalool, and control (DEX) with NO receptor. The higher binding affinity of cis-verbenyl acetate is attributed to the conventional hydrogen bonds formed with TYR186 and LYS187, Pi-alkyl interaction with HIS181, and finally, alkyl interaction with ILE243 and LYS187 (Figure 3a). The number of Pi-sigma interactions (Pi-alkyl) which largely involves charge transfer helps in firmly binding linalool and $\beta$-elemene with the receptor residues TYR188, TYR159, and PHE245. Similar alkyl interactions with ILE297, ILE160, PRO298, and LEU299 are shown for both $\beta$-elemene and linalool, but the latter has a unique conventional hydrogen bonding with TYR159 and carbon-hydrogen bonding with GLY158 (Figure 3b,c). The similarity of interactions and types of bonds were the main reasons for the close binding affinity and free energy between each ligand and the control (DEX), indicating a good antioxidant ability of the tested molecules. According to the literature, other ligands with different chemical structures have shown an antioxidant activity due to the similarity of interactions and active site with the current study $[10,32]$. For example, similar to the interacted residues of Figure 3, Costa et al. [10] showed that ASP179, TYR188, ILE243, and HIS181 residues of NO receptor interact with all caffeine analogs used as ligands. In another study, Lountos et al. [32] have shown an interaction between TYR188, ILE160, ILE243, and ASP179 residues and 5-ADP, consistently with our findings.

It is well-known that bioactive compounds containing a phenolic ring and hydroxyl group exhibit a higher antioxidant activity [29]. However, the results of the present molecular docking study open prospects for the use of non-oxygenated and non-phenolic terpenes as efficient antioxidants by reducing oxidative stress. In vivo studies will be necessary to reveal the behavior of different non-oxygenated terpenes as antioxidants since in vitro techniques like DPPH, FRAP, and others are not adequate to show the activity of such categories in reducing oxidative stress. 


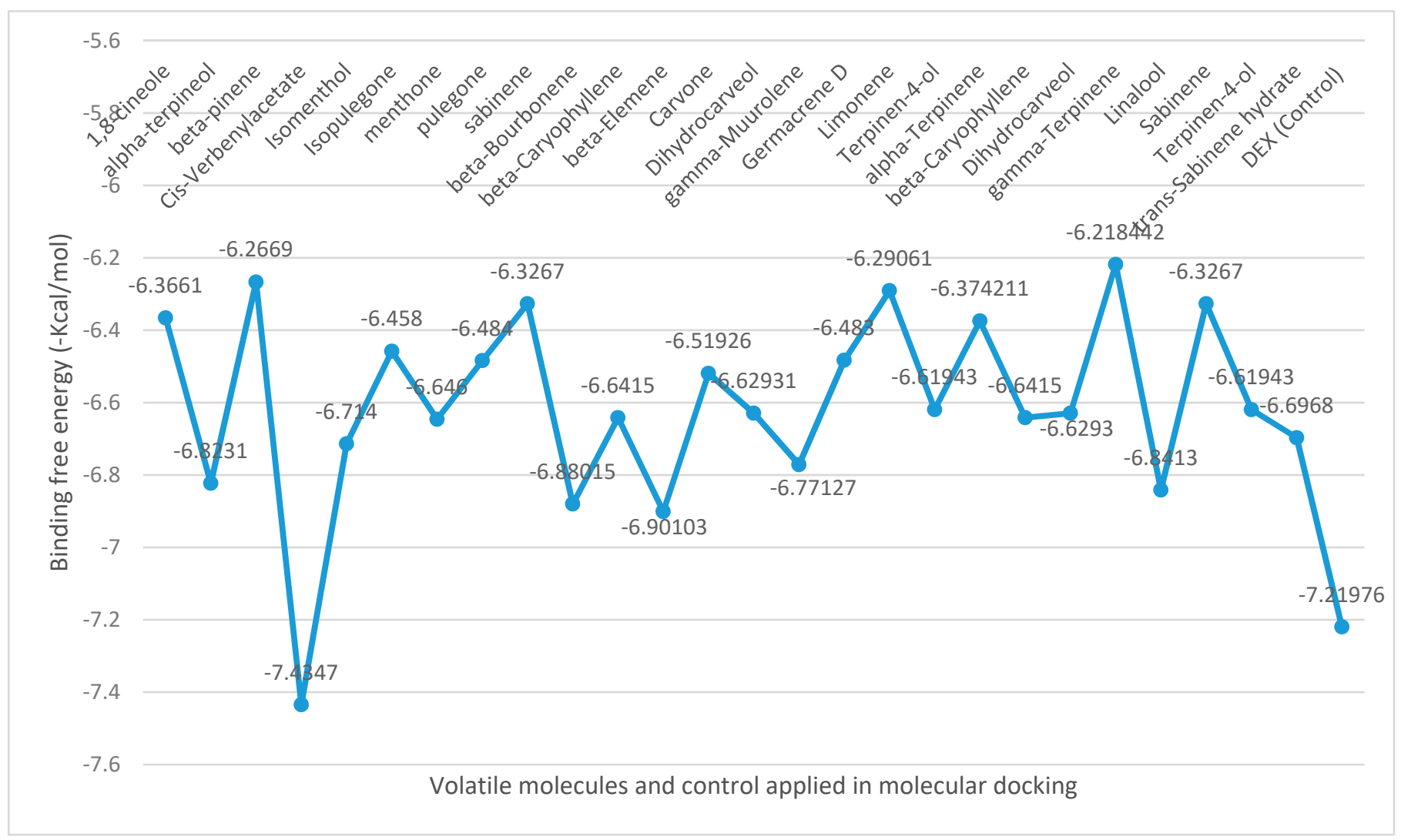

Figure 2. Binding free energy values calculated through the molecular docking of the major volatiles identified in lamiaceous plants and $\mathrm{NO}$ receptor. 


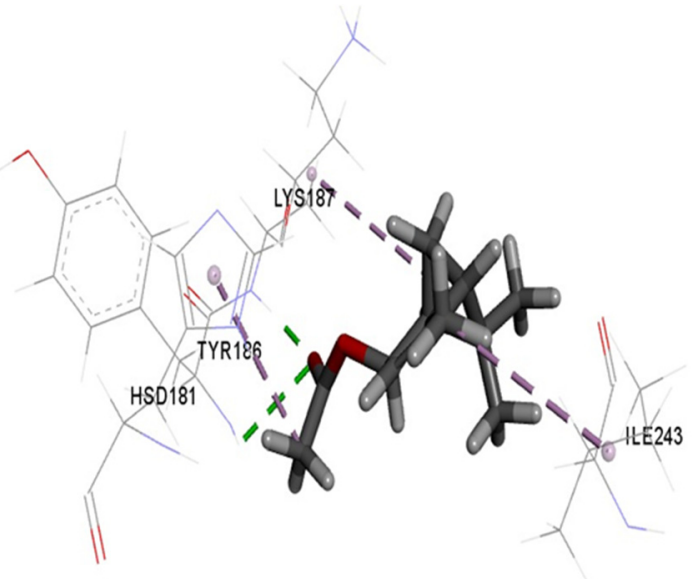

(a)

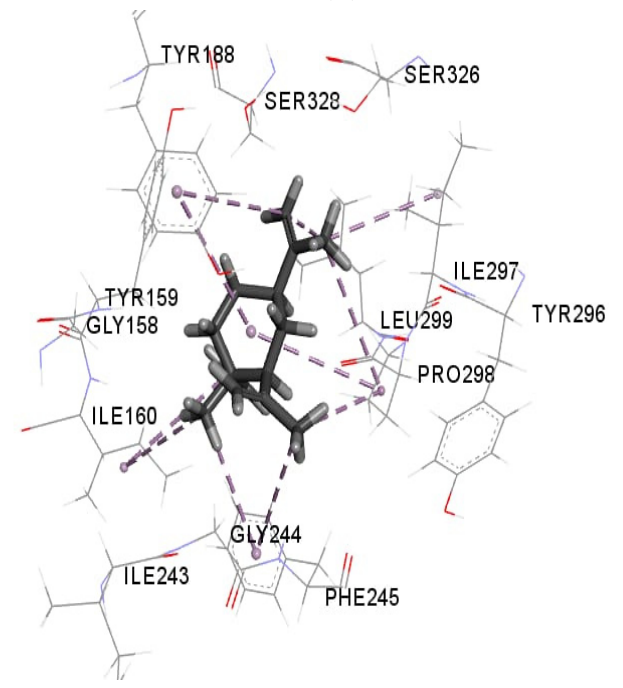

(b)

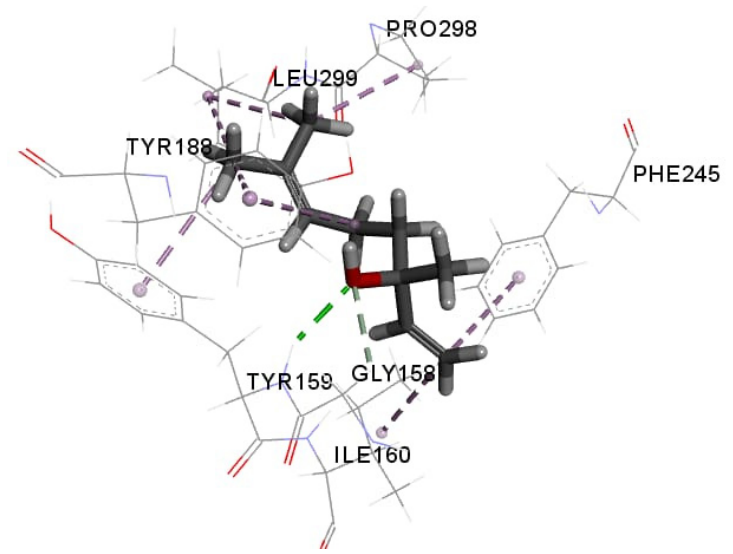

(c)

Figure 3. Cont. 


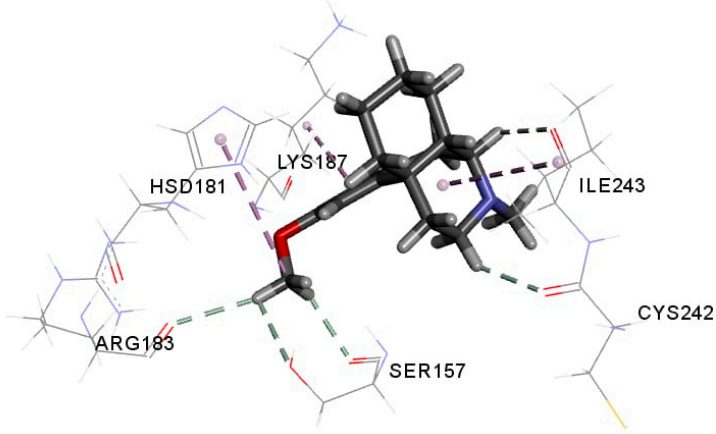

(d)

Figure 3. Interactions of (a) cis-verbenyl acetate, (b) $\beta$-elemene, (c) linalool, and (d) DEX (control) with $\mathrm{NO}$ receptor.

\section{Materials and Methods}

\subsection{Plant Materials}

Mentha longifolia L. (Madany or Habak), Mentha spicata L. (Balady), and Origanum majorana L. (Doosh) were collected from Abyar Ali, Madinah, Saudi Arabia, in March 2018. Plant samples were identified by a taxonomist at the Department of Botany, Faculty of Science, Taif University and deposited in Madinah Region Municipality-Quality AgencyFood and Environment Laboratory, Madinah, Saudi Arabia with voucher specimens' numbers AF-36004261-2018, AF-36004262-2018, and AF-36004263-2018.

\subsection{Chemicals}

Diethyl ether and methanol were purchased from Fisher Chemicals (Pittsburgh, USA). The mixture of n-alkanes $\mathrm{C}_{6}-\mathrm{C}_{26}$, authentic compounds, sodium bicarbonates, linoleic acid ( $\geq 99 \%$ ), Tween $40, \beta$-carotene ( $\geq 97 \%$ ), Folin-Ciocalteu reagent for total phenolics, 2,2'-diphenyl-1-picrylhydrazyl (DPPH),2,2' —azino-bis-3-ethylbenzthiazoline-6-sulphonic acid (ABTS, purity $>99 \%$ ), methanol, TBHQ (tert-Butyl hydroquinone), and gallic acid were obtained from Sigma Aldrich Chemical Co. (St. Louis, MO, USA).

\subsection{Extraction of the Volatile Components}

Air-dried aerial parts of M. longifolia, M. spicata, and O. majorana $(100 \mathrm{~g})$ in three replicates that were cut into small pieces and subjected to hydrodistillation for $3 \mathrm{~h}$, using a Clevenger type apparatus. The volatile-compounds extract was dried using anhydrous sodium sulfate, stored in airtight glass vials covered with aluminum foil at $\left(-20^{\circ} \mathrm{C}\right)$ until analysis [1].

\subsection{Gas Chromatography-Mass Spectrometry (GC-MS)}

The components of the essential oil obtained using hydrodistillation were analyzed using a GC-MS apparatus. The separation was performed on a Trace GC Ultra Chromatography system (Thermo Scientific, USA) equipped with an ISQ-mass spectrometer (Thermo Scientific, USA) with a $60 \mathrm{~m} \times 0.25 \mathrm{~mm} \times 0.25 \mu \mathrm{m}$-thick TG-5MS capillary column (Thermo Scientific, USA). The column separation was programmed from $50{ }^{\circ} \mathrm{C}$ with a holding time of $3 \mathrm{~min}$, and then the temperature was increased at a rate of $4{ }^{\circ} \mathrm{C}$ per min to $140{ }^{\circ} \mathrm{C}$ with a holding time of $5 \mathrm{~min}$. After that, the temperature was increased at $6{ }^{\circ} \mathrm{C}$ per minute to $260^{\circ} \mathrm{C}$ for a 5 -min isothermal holding time. The injector temperature was $180^{\circ} \mathrm{C}$, the ion source temperature was $200^{\circ} \mathrm{C}$, and the transition line temperature was $250^{\circ} \mathrm{C}$. The carrier gas was helium with a constant flow rate of $1.0 \mathrm{~mL} / \mathrm{min}$. The mass spectrometer had a scan range from $\mathrm{m} / \mathrm{z} 40-450$, and the ionization energy was set at $70 \mathrm{eV}$. The identification of compounds was based on matching with the MS computer library (NIST library, 2005 version) and compared with those of authentic compounds and published data [33]. The relative percentage of the oil constituents was calculated from the GC peak areas. Kovat's 
index was calculated for each compound, using the retention times of a homologous series of $\mathrm{C}_{6}-\mathrm{C}_{26} \mathrm{n}$-alkanes and by matching with the literature $[4,7,11,15,16,19,22,23]$.

\subsection{Antioxidant Activity Measurements}

DPPH radical scavenging assay: Potential antioxidant activity of the oils under investigation was assessed according to the methods reported by Hatano et al. [34] in comparison to a synthetic antioxidant used in the food industry, tert-butyl hydroquinone (TBHQ). Serial of essential oils were applied with concentrations of $0.5-10 \mathrm{mg} / \mathrm{mL}$ of methanol. After incubation with DPPH solution, the absorbance was measured at $517 \mathrm{~nm}$ using a spectrophotometer (Evolution 300 Thermo UV-VIS); all tests were run in three replicates, and the results were averaged. A positive control (TBHQ) at concentrations ranging from $0.1-5 \mathrm{mg} / \mathrm{mL}$ was applied in parallel. The radical scavenging activity of extracts was expressed as the IC50 value $(\mathrm{mg} / \mathrm{mL})$, i.e., the concentration necessary to decrease the DPPH concentration by $50 \%$.

$\beta$-Carotene bleaching assay: The antioxidant activity of the oils was determined using a $\beta$-carotene/linoleic acid system, as described by Taga et al. [35] in comparison to TBHQ. Different concentrations of oils ranging from $1-100 \mathrm{mg} / \mathrm{mL}$ were applied to the $\beta$-carotene/linoleic acid system, where the absorbance was measured at $470 \mathrm{~nm}$ over a 60-min period. All determinations were performed in triplicate.

The ABTS free radical-scavenging assay: The antioxidant activity of the oils under investigation was determined by their ability to decolorize the radical cation $\left(\mathrm{ABTS}^{\bullet+}\right)$ as previously detailed [36]. The method comprises the addition of $180 \mu \mathrm{L}$ of ABTS solution to $20 \mu \mathrm{L}$ of the sample solution in methanol at different concentrations $(1-100 \mu \mathrm{g} / \mathrm{mL})$. After $10 \mathrm{~min}$, the percentage inhibition at $734 \mathrm{~nm}$ was calculated for each concentration relative to a blank absorbance (methanol). The scavenging capability of ABTS was calculated using the following equation:

$$
\mathrm{ABTS}^{\bullet+} \text { scavenging activity }(\%)=\left(\left(\mathrm{A}_{\text {Control }}-\mathrm{A}_{\text {Sample }}\right) / \mathrm{A}_{\text {Control }}\right) \times 100 .
$$

Total phenolic content: Total phenolic content of the essential oils was determined using the Folin-Ciocalteu reagent according to a method modified from Singleton et al. [37] using gallic acid as the standard. The reaction mixtures were incubated in a thermostat at $45^{\circ} \mathrm{C}$ for $45 \mathrm{~min}$ before the absorbance at $765 \mathrm{~nm}$ was measured. The total phenolic contents were calculated based on the calibration curve of gallic acid and expressed as gallic acid equivalents (GAE), in milligrams per gram of the sample.

\subsection{Molecular Docking}

A flexible molecular docking study was carried out on NADPH oxidase (NO) responsible for the production of ROS using the Swissdock server, accessed on 12 May 2021 (www.swissdock.ch/docking\#) based on grid center coordinates and size described by Costa et al. [10]. NO-Protein was obtained from the Protein Data Bank (PDB) with code (2CDU) and prepared as a receptor by removing waters and co-crystallized ligands (ADP and FAD) then protonated using Pymol software [38]. Meanwhile, the 3d structure of ligands downloaded from the PUBCHEM database, accessed on 12 May 2021 (http:/ / pubchem.ncbi.nlm.nih.gov/) were optimized using the MMFF94 force field by ChemDraw Software (Ver. 18.0) [39]. Docking results $(\Delta G)$ were viewed using Chimera 1.14 software, while profiles of interaction and visualization were performed using Discovery Studio software (Ver. 20.1.0.19295) [40].

\subsection{Statistical Analysis}

Statistical analyses were performed using SPSS software version 16 . The data were expressed as mean $\pm \mathrm{SD}$ and analyzed using the student's t-test and variance analysis. 


\section{Conclusions}

In the present study, volatiles of dried Mentha longifolia L., Mentha spicata L., and Origanum majorana L. cultivated in Madinah Monawara, KSA, were extracted using hydrodistillation followed by separation and identification using GC-MS. Pulegone and 1,8-cineole were the major components in M. longifolia oil, while carvone and limonene predominate in M. spicata oil and terpin-4-ol in O. majorana oil. Madinah O. majorana oil was associated with a higher scavenging ability and a more significant inhibiting effect toward the oxidation of linoleic acid compared to M. spicata and M. longifolia, due to the presence of many volatiles with phenolic nature and, therefore, antioxidant activity as well as higher total phenolic content. A molecular docking study revealed that non-oxygenated terpenes display higher activity in reducing oxidative stress through interaction with NADPH oxidase residues. In vivo studies will be necessary to reveal the behavior of different non-oxygenated terpenes as antioxidants since the in vitro techniques are not adequate to show the activity of such categories in reducing oxidative stress.

Author Contributions: Conceptualization, project administration, molecular docking, and writingoriginal draft, A.F.; methodology, investigation, formal analysis, statistical and data curation, A.F., H.S., H.A. and M.M.; writing-review and editing, N.A. All authors have read and agreed to the published version of the manuscript.

Funding: This work was supported by the Deanship of Scientific Research, at Princess Nourah bint Abdulrahman University, through the Fast-Track Research Funding Program.

Data Availability Statement: The data presented in this study are available in this article.

Acknowledgments: The authors extend their appreciation to the Deanship of Scientific Research, at Princess Nourah bint Abdulrahman University, for the facilities that were provided.

Conflicts of Interest: The authors declare no conflict of interest.

Sample Availability: Samples of the compounds are available from the authors.

\section{References}

1. Farouk, A.; Fikry, R.; Mohsen, M. Chemical Composition and Antioxidant Activity of Ocimum basilicum L. Essential Oil Cultivated in Madinah Monawara, Saudi Arabia and its Comparison to the Egyptian Chemotype. J. Essent. Oil-Bear. Plants 2016, 19, 1119-1128. [CrossRef]

2. Al-Ali, K.; Abdelrazik, M.; Alghaithy, A.; Diab, A.; El-Beshbishy, H.; Baghdadi, H. Antimutagenic and anticancer activity of Al Madinah Alhasawy mint (Mentha longifolia) leaves extract. Pak. J. Biol. Sci. 2014, 17, 1231-1236. [CrossRef] [PubMed]

3. Ahmed, A.M.; Ozbak, H.A.; Hemeg, H.A. Effect of essential oil of traditional two Saudi mint types and its possible role in cardiovascular and throat health. Int. J. Clin. Exp. Med. 2015, 15, 8060-8068.

4. Ibrahim, S.; Abdallah, H.; Mohamed, G.; Farag, M.; Alshali, K.; Alsherif, E.; Ross, S. Volatile oil profile of some lamiaceous plants growing in Saudi Arabia and their biological activities. Z. Naturforsch. C 2017, 72, 35-41. [CrossRef] [PubMed]

5. Tafrihi, M.; Imran, M.; Tufail, T.; Gondal, T.A.; Caruso, G.; Sharma, S.; Sharma, R.; Atanassova, M.; Atanassov, L.; ValereTsouhFokou, P.; et al. The Wonderful Activities of the Genus Mentha: Not Only Antioxidant Properties. Molecules 2021, $26,1118$. [CrossRef] [PubMed]

6. Anwar, F.; Alkharfy, K.M.; Najeeb-ur-Rehman; Adam, E.H.K.; Gilani, A. Chemo-geographical variations in the composition of volatiles and the biological attributes of Mentha longifolia (L.) Essential oils from Saudi Arabia. Int. J. Pharmacol. 2017, 13, 408-424. [CrossRef]

7. Salman, M.; Abdel-Hameed, E.S.; Bazaid, S.A.; Dabi, M.M. Chemical composition for hydrodistillation essential oil of Mentha longifolia by gas chromatography-mass spectrometry from north regions in Kingdom of Saudi Arabia. Pharm. Chem. 2015, 7, 34-40.

8. Hajlaoui, H.; Mighri, H.; Aouni, M.; Gharsallah, N.; Kadri, A. Chemical composition and in vitro evaluation of antioxidant, antimicrobial, cytotoxicity and anti-acetylcholinesterase properties of Tunisian Origanum majorana L. essential oil. Microb. Pathog. 2016, 95, 86-94. [CrossRef]

9. Gabr, S.K.; Bakr, R.O.; Mostafa, E.S.; El-Fishawy, A.M.; El-Alfy, T.S. Antioxidant activity and molecular docking study of Erythrina $\times$ neillii polyphenolics. S. Afr. J. Bot. 2019, 121, 470-477. [CrossRef]

10. Costa, J.D.S.; Ramos, R.D.S.; Costa, K.D.S.L.; Brasil, D.D.S.B.; Silva, C.H.T.D.P.D.; Ferreira, E.F.B.; Borges, R.D.S.; Campos, J.M.; Macêdo, W.J.D.C.; Santos, C.B.R.D. An In Silico Study of the Antioxidant Ability for Two Caffeine Analogs Using Molecular Docking and Quantum Chemical Methods. Molecules 2018, 23, 2801. [CrossRef] [PubMed] 
11. Elansary, H.O.; Ashmawy, N.A. Essential Oils of Mintbetween Benefits and Hazards. J. Essent. Oil-Bear. Plants 2013, 16, 429-438. [CrossRef]

12. Hajlaoui, H.; Snoussi, M.; Ben Jannet, H.; MIghri, Z.; Bakhrouf, A. Comparison of chemical composition and antimicrobial activities of Mentha longifolia L. ssp. longifolia essential oil from two Tunisian localities (Gabes and Sidi Bouzid). Ann. Microbiol. 2008, 58, 513. [CrossRef]

13. Sharopov, F.S.; Sulaimonova, V.A.; Setzer, W.N. Essential oil composition of Mentha longifolia from wild populations growing in Tajikistan. J. Med. Act. Plants 2012, 1, 76-84. Available online: http://scholarworks.umass.edu/jmap/vol1/iss2/6 (accessed on 9 March 2021).

14. Ali-Shtayeh, M.S.; Jamous, R.M.; Abu-Zaitoun, S.Y.; Khasati, A.I.; Kalbouneh, S.R. Biological Properties and Bioactive Components of Mentha spicata L. Essential Oil: Focus on Potential Benefits in the Treatment of Obesity, Alzheimer's Disease, Dermatophytosis, and Drug-Resistant Infections. Evid. Based Complement. Alternat. Med. 2019, 2019, 3834265. [CrossRef]

15. Bardaweel, S.K.; Bakchiche, B.; ALSalamat, H.A.; Rezzoug, M.; Gherib, A.; Flamini, G. Chemical composition, antioxidant, antimicrobial and Antiproliferative activities of essential oil of Mentha spicata L. (Lamiaceae) from Algerian Saharan atlas. BMC Complement. Altern. Med. 2018, 18, 201. [CrossRef] [PubMed]

16. Buleandra, M.; Oprea, E.; Popa, D.E.; David, I.G.; Moldovan, Z.; Mihai, I.; Badea, I.A. Comparative Chemical Analysis of Mentha piperita and M. spicata and a Fast Assessment of Commercial Peppermint Teas. Nat. Prod. Commun. 2016, 11, 551-555. [CrossRef]

17. Raina, A.P.; Negi, K.S. Essential oil composition of Origanum majorana and Origanum vulgare ssp. hirtum growing in India. Chem. Nat. Compd. 2012, 47, 1015-1017. [CrossRef]

18. Vági, E.; Simándi, B.; Suhajda, Á.; Héthelyi, É. Essential oil composition and antimicrobial activity of Origanum majorana L. extracts obtained with ethyl alcohol and supercritical carbon dioxide. Food Res. Int. 2005, 38, 51-57. [CrossRef]

19. Jiang, Z.-T.; Li, R.; Wang, Y.; Chen, S.-H.; Guan, W.-Q. Volatile Oil Composition of Natural Spice, Origanum majorana L. Grown in China. J. Essent. Oil-Bear. Plants 2011, 14, 458-462. [CrossRef]

20. Freire, J.M.; Cardoso, M.G.; Batista, L.R.; Andrade, M.A. Essential oil of Origanum majorana L., Illicium verum Hook. f. and Cinnamomum zeylanicum Blume: chemical and antimicrobial characterization. Rev. Bras. Plantas Med. 2011, 13, $209-214$. [CrossRef]

21. Turek, C.; Stintzing, F. Stability of Essential Oils: A Review. Compr. Rev. Food Sci. Food Saf. 2013, 12, 40-53. [CrossRef]

22. Soliman, F.M.; Yousif, M.F.; Zaghloul, S.S.; Okba, M.M. Seasonal variation in the essential oil composition of Origanum majorana L. cultivated in Egypt. Z. Naturforsch. C. J. Biosci. 2009, 64, 611-614. [CrossRef] [PubMed]

23. Abbasi-Maleki, S.; Kadkhoda, Z.; Taghizad-Farid, R. The antidepressant-like effects of Origanum majorana essential oil on mice through monoaminergic modulation using the forced swimming test. J. Tradit. Complement. Med. 2020, 10, 327-335. [CrossRef]

24. Meloni, D.; Lescano, J.; Arraiza, M.; Beltrán, R. Yield, chemical composition and functional properties of essential oils from Mentha spicata (Lamiaceae) in Santiago del Estero, Argentina. UNED Res. J. 2019, 11, 327-333. [CrossRef]

25. Gulluce, M.; Sahin, F.; Sokmen, M.; Ozer, H.; Daferera, D.; Sokmen, A.; Polissiou, M.; Adiguzel, A.; Ozkan, H. Antimicrobial and antioxidant properties of the essential oils and methanol extract from Mentha longifolia L. ssp. longifolia. Food Chem. 2007, 103, 1449-1456. [CrossRef]

26. Saba, I.; Anwar, F. Effect of Harvesting Regions onPhysico-chemical and Biological Attributes of Supercritical Fluid-Extracted Spearmint (Menthaspicata L.) Leaves Essential Oil. J. Essent. Oil-Bear. Plants 2018, 21, 400-419. [CrossRef]

27. Torres-Martínez, R.; García-Rodríguez, Y.M.; Ríos-Chávez, P.; Saavedra-Molina, A.; López-Meza, J.E.; Ochoa-Zarzosa, A.; Garciglia, R.S. Antioxidant Activity of the Essential Oil and its Major Terpenes of Saturejamacrostema (Moc. and Sessé ex Benth.). Briq. Pharmacogn. Mag. 2018, 13, S875-S880. [CrossRef]

28. Kasrati, A.; Alaoui, J.C.; Bekkouche, K.; Wohlmuth, H.; Leach, D.; Abbad, A. Comparative evaluation of antioxidant and insecticidal properties of essential oils from five Moroccan aromatic herbs. J. Food Sci. Technol. 2015, 52, 2312-2319. [CrossRef]

29. Pripdeevech, P.; Chumpolsri, W.; Suttiarrorn, P.; Wongpornchai, S. The Chemical Composition and Antioxidant Activities of Basil from Thailand Using Retention Indices and Comprehensive Two-Dimensional Gas Chromatography. J. Serbian Chem. Soc. 2010, 75, 1503-1513. [CrossRef]

30. Souza, C.F.; Baldissera, M.D.; Silva, L.L.; Geihs, M.A.; Baldisserotto, B. Is monoterpene terpinen-4-ol the compound responsible for the anesthetic and antioxidant activity of Melaleuca alternifolia essential oil (tea tree oil) in silver catfish? Aquaculture 2018, 486, 217-223. [CrossRef]

31. Hossain, M.B.; Camphuis, G.; Aguiló-Aguayo, I.; Gangopadhyay, N.; Rai, D.K. Antioxidant activity guided separation of major polyphenols of marjoram (Origanum majorana L. ) using flash chromatography and their identification by liquid chromatography coupled with electrospray ionization tandem mass spectrometry. J. Sep. Sci. 2014, 37, 3205-3213. [CrossRef]

32. Lountos, G.T.; Jiang, R.; Wellborn, W.B.; Thaler, T.L.; Bommarius, A.S.; Orville, A.M. The crystal structure of NAD(P)H oxidase from lactobacillus sanfranciscensis: Insights into the conversion of $\mathrm{O} 2$ into two water molecules by the flavoenzyme. Biochemistry 2006, 2006, 9648-9659. [CrossRef] [PubMed]

33. Adams, R. Identification of Essential Oil Components by Gas. Chromatography/Mass Spectroscopy, 4th ed.; Allured Publishing Corporation: Carol Stream, IL, USA, 2007.

34. Hatano, T.; Kagawa, H.; Yasuhara, T.; Okuda, T. Two new flavonoids and other constituents in licorice root: Their relative astringency and radical scavenging effects. Chem. Pharm. Bull. 1988, 36, 2090-2097. [CrossRef] [PubMed] 
35. Taga, M.; Miller, E.; Pratt, D. Chia Seeds as Source of Natural Lipid Antioxidants. J. Am. Oil Chemists' Soc. 1984, 61, 928-931. [CrossRef]

36. Musa, A.; El-Massry, K.F.; El-Ghorab, A.H.; Farouk, A.; Ali, H.M.; Abdelgawad, M.A.; Mostafa, E.M. Essential Oil Composition of Cistanche tubulosa and Their Antioxidant and Antimicrobial Potentials. Rec. Nat. Prod. 2021, 15, 301-311. [CrossRef]

37. Singleton, V.; Orthofer, R.; Lamuela-Raventos, R. Analysis of Total Phenols and Other Oxidation Substrates and Antioxidants by Means of Folin-Ciocalteu Reagent. Meth. Enzymol. 1999, 299, 152-178. [CrossRef]

38. Schrödinger, L.; DeLano, W. PyMOL. 2020. Available online: http:/ / www.pymol.org/pymol (accessed on 14 May 2021).

39. Cousins, K.R. ChemDraw Ultra 9.0. CambridgeSoft, 100 CambridgePark Drive, Cambridge, MA 02140. www. cambridgesoft.com. See Web site for pricing options. J. Am. Chem. Soc. 2005, 127, 4115-4116. [CrossRef]

40. Pettersen, E.F.; Goddard, T.D.; Huang, C.C.; Couch, G.S.; Greenblatt, D.M.; Meng, E.C.; Ferrin, T.E. UCSF Chimera-a visualization system for exploratory research and analysis. J. Comput. Chem. 2004, 13, 1605-1612. [CrossRef] 